\title{
Editorial
}

\section{História e histórias da pós-graduação em educação no Brasil}

A análise da história da pós-

graduação em educação no Brasil poderia

ser feita a partir de diversas perspecti-

vas. Poder-se-ia resgatá-la do ponto de

vista da legislação, vendo os documentos

fundantes e aqueles que provocaram

inflexões ou reencaminhamentos. É o

caso do parecer $n^{\circ} 977 / 65$, do antigo

Conselho Federal de Educação (CFE).

Poder-se-ia também fazer um esforço de

recuperação dos principais

direcionamentos emanados dos cinco

planos nacionais de pós-graduação

elaborados pela Coordenação de

Aperfeiçoamento de Pessoal de Nível

Superior (CAPES). Poder-se-ia ainda

analisar as razões por que uma iniciativa

do vulto da pós-graduação teve o seu

maior impulso e expansão em pleno

regime militar.

De outra perspectiva, poder-se-ia trazer para a discussão o principal paradigma que predominou nestes quarenta anos de história da pósgraduação: a formação de professores ou a busca de suprir os quadros docentes das universidades brasileiras com mestres e doutores, formação essa algumas vezes organicamente ligada à formação de pesquisadores.

No entanto, seja qual for o ângulo de análise escolhido, estaremos tratando de "vias interrompidas, de possibilidades bloqueadas, de itinerários desprezados que devem ser compreendidos e afirmados e indicados como alternativas possíveis não só do passado, mas também do presente, pelo menos como alternativas teóricas, percursos diferentes, integradores e corretores de um modelo”. ${ }^{1}$

No caso específico da pósgraduação em educação, optamos por recuperar essa história, em primeiro lugar, pela rememoração da importância inconteste dos documentos legais que a institucionalizaram, pelo significado de algumas experiências e iniciativas em sua implantação, e pelo papel desempenhado por alguns professores que marcaram o caráter efetivo dos estudos pós-graduados. Não podíamos deixar de destacar a própria atuação da Associação

Nacional de Pós-Graduação e Pesquisa em Educação (ANPEd), no esforço de dar caráter científico à produção da área, nem de refletir sobre as decisivas influências do sistema de avaliação, garantidor de indiscutível qualidade da

${ }^{1}$ CAMBI, Franco, (1999). História da pedagogia. São Paulo: Ed. UNESP, p. 38. pós-graduação brasileira, em alguns momentos terreno de disputa pela hegemonia entre as áreas e privilégios na repartição dos recursos.

Este número especial da Revista Brasileira de Educação aborda os quarenta anos da implantação da pósgraduação stricto sensu em educação no Brasil. No final de 1965 foi aprovado o primeiro mestrado em educação, na Pontifícia Universidade Católica do Rio de Janeiro (PUC-Rio). Desde esse primeiro curso até o presente momento, mais de setenta programas foram reconhecidos, passando a fazer parte do Sistema Nacional de Pós-Graduação. Processos, fatos, iniciativas, aspectos legais, personagens, atores e autores, com relatos e reflexões a respeito desse denso, rico e contraditório processo preenchem as páginas deste número. Cada um dos textos que dele faz parte constitui-se em uma espécie de link, por meio do qual é possível acessar uma série de fontes que compõem o hipertexto formador da história da pósgraduação em educação em nosso país.

$\mathrm{O}$ artigo inicial, de Carlos Roberto Jamil Cury, “Quadragésimo ano do parecer CFE nº 977/65”, elaborado com cuidadosa pesquisa nos 
documentos legais, historia a gestação desse parecer, que define a pósgraduação brasileira, e do parecer CFE $n^{\circ} 77 / 65$, que trata do reconhecimento dos cursos de pós-graduação, ambos emanados do antigo CFE. Por sua relevância e por sua relação direta com a criação e a expansão da pósgraduação no país, uma vez que formou o balizamento legal da estrutura e do funcionamento dos cursos, o parecer CFE n 977/65 foi reproduzido na íntegra, na seção Documento. Ademais, embora outras peças legais tenham surgido e embora estejamos na vigência do recémaprovado $5^{\circ}$ Plano Nacional de PósGraduação para o período 2005-2010, essa legislação básica continua atuante. Por si só, essa republicação não se justificaria, pois pode ser obtida em outras fontes. Aqui ganha sentido pelo fato de poder ser consultada concomitantemente à leitura de Cury, que, na conclusão de seu artigo, afirma ser o parecer CFE no 977/65 o único documento doutrinário da pós-graduação, nestes quarenta anos.

O depoimento de Menga Lüdke, baseado em sua experiência, na consulta a documentos e na manifestação de colegas, retoma aspectos do entrecruzamento dos modelos de pósgraduação europeu (particularmente o francês) e norte-americano no processo de constituição da pós-graduação stricto sensu em educação brasileira. A partir dessas influências cruzadas, detecta a emergência de um sistema caracterizado pela hibridez, no qual ainda podem ser visualizadas as especificidades dos sistemas francês e norte-americano - no que diz respeito à relação orientador/orientando, ao número de créditos, à estrutura disciplinar e às características das teses e dissertações -, mas identifica também sinais de uma pós-graduação autóctone, resultante de uma síntese dos dois sistemas.

Na busca de compreender os importantes passos iniciais da pósgraduação no Brasil, os colegas Dermeval Saviani e Maria de Lourdes de Albuquerque Fávero foram convidados para resgatar, respectivamente, o protagonismo e a contribuição dos professores Joel Martins, na Pontifícia Universidade Católica de São Paulo (PUC-SP), e Durmeval Trigueiro Mendes, da PUC-Rio e do Instituto de Estudos Avançados de Educação da Fundação Getúlio Vargas (IESAEFGV). A leitura desses dois textos evidencia a importância desses dois pensadores-educadores no que diz respeito a iniciativas institucionais e a produções teóricas, às quais muito devemos daquilo que somos e fazemos hoje.

No artigo intitulado “A Faculdade Interamericana de Educação na expansão da pós-graduação em educação no Brasil”, Clovis R. J. Guterres e Oswaldo Alonso Rays analisam uma singular experiência de pós-graduação com características do que se poderia considerar hoje “inserção internacional”. Por sete anos, no início dos anos de 1970, a Organização dos Estados Americanos (OEA) deu as normas para criação e manteve financeiramente um curso de mestrado em educação na Universidade Federal de Santa Maria (UFSM), ao qual acorreram alunos de diversos países da
América Latina. Entre outros aspectos, os autores descrevem o funcionamento da Faculdade Interamericana de Educação e analisam as razões da sua não-continuidade e sua influência para a afirmação dos estudos pós-graduados no interior do Rio Grande do Sul.

De certa forma, esse artigo é complementado pelo depoimento de Arnon de Andrade, historiando a implantação do mestrado em tecnologia educacional, no Instituto Nacional de Pesquisas Espaciais (INPE), ligado à Presidência da República, em São José dos Campos, e mostrando os desdobramentos desse mestrado na criação da pós-graduação em educação da Universidade Federal do Rio Grande do Norte (UFRN). Esses dois mestrados pioneiros, cada um com sua especificidade, são comumente citados nos trabalhos sobre a implantação da pós-graduação em educação, mas é a primeira vez que são historicizados.

Por sua vez Alceu Ravanello Ferraro, no artigo “A ANPEd, a pósgraduação, a pesquisa e a veiculação da produção intelectual na área de educação”, toma seu período de gestão como presidente da ANPEd (19891993) como “ângulo de visão” e, com base em rigorosa e detalhada pesquisa documental, ajuda-nos a compreender a trajetória da associação, em passado recente. Analisa inicialmente o final dos anos de 1980, quando a ANPEd, em suas reuniões anuais e, em conjunto com o Centro de Estudos Educação e Sociedade (CEDES) e com a Associação Nacional de Educação (ANDE), nas Conferências Brasileiras de Educação (CBE), colaborou intensa e qualificadamente com a Assembléia 
Constituinte de 1987-1988 e com o

início de preparação da nova Lei de

Diretrizes e Bases da Educação

Nacional (LDB). E contrapõe ao

esforço feito no início dos anos de

1990 para equilibrar a participação

política da ANPEd com o necessário

caráter científico de uma associação

acadêmica. É um artigo que não pode

deixar de ser lido, caso se queira

entender o papel dessa associação tanto

nas lutas políticas quanto no processo

de afirmação da área de educação,

particularmente a partir da constituição

dos grupos de trabalho, da criação do

comitê científico, do formato das

reuniões anuais, da atuação do Fórum

de Coordenadores do Programas de

Pós-Graduação em Educação, da

criação da Revista Brasileira de

Educação, entre outros aspectos.

De outro ponto de vista, abordan-

do período imediatamente anterior

(1981-1992), o depoimento de

Bernardete Gatti relembra a atuação

conjunta do Conselho Nacional de

Desenvolvimento Científico e Tecnoló-

gico (CNPq), da Financiadora de

Estudos e Projetos (FINEP), do

Instituto Nacional de Estudos e

Pesquisas Educacionais Anísio Teixeira

(INEP) e da Coordenação de Aperfei-

çoamento de Pessoal de Ensino

Superior (CAPES), na implantação do

Programa de Intercâmbio na Área de

Pesquisa Educacional, nos moldes

existentes para a área de saúde. O

objetivo maior era a melhoria da

qualidade da pesquisa em educação

nos país, por meio dos profissionais

nela envolvidos, da permuta de

informações e da realização de

trabalhos de pesquisa em colaboração.
Dispunha, para tanto, de recursos

específicos e realizou-se durante todo o

período, por meio de “estágios”

temáticos, em diferentes instituições

universitárias. Inicialmente coordenado

pela Fundação Carlos Chagas, a partir

de 1992 ficou sob a responsabilidade

da ANPEd, que transformou os

“estágios” em “seminários de pesqui-

sa” realizados por diferentes grupos de

trabalho, o que garantiu a eles - $\mathrm{e}$

ainda garante, nos dias atuais -

eficiente forma de definição e aprofun-

damento dos respectivos trabalhos de pesquisa.

Abordando o tema da avaliação, José Silvério Baía Horta e Maria Célia Marcondes de Moraes, do privilegiado “posto de observação” enquanto representantes da área de educação na CAPES, entre os anos de 1998 e 2003 , elaboram um denso texto, com riqueza de dados, sobre o processo de avaliação do qual foram coordenadores, tornando públicas determinadas decisões que nem sempre chegam ao conhecimento dos responsáveis pelos programas de pós-graduação. Ao mesmo tempo evidenciam aspectos da própria área de educação que merecem ser analisados, pois apontam para debilidades que a prejudicam no momento em que são considerados aspectos determinantes na avaliação, com conseqüências diretas no fomento dos programas, por parte da CAPES, do CNPq e das fundações estaduais de apoio à pesquisa. Outro mérito desse texto é a possibilidade de os responsáveis pela pós-graduação em educação se darem conta dos envolvimentos e disputas entre áreas, especialmente a clara hegemonia das áreas das ciências exatas, sem deixar de ter presente que também há disputas internas na grande área das ciências sociais e humanas. Esperamos que essa análise esclareça os coordenadores dos programas de pós-graduação em educação acerca do processo avaliativo e lhes permita um posicionamento mais crítico e consciente em relação a ele.

Abordando a mesma questão da avaliação levantada por esses autores, Betania Leite Ramalho e Vicente de Paulo Carvalho Madeira analisam a “A pós-graduação em educação no Norte e Nordeste: desafios, avanços e perspectivas”, enfatizando a maneira como os programas se estruturaram e reagiram ao processo e aos resultados das avaliações da CAPES, a partir do biênio 1995-1996.

Inserimos neste número as entrevistas com Juracy C. Marques, professora aposentada da Universidade Federal do Rio Grande do Sul (UFRGS), e Maria Julieta Costa Calazans, professora aposentada da UFRN e da FGV-Rio. Suas trajetórias, em muitos momentos ocupando posições opostas, convergem no sentido de terem exercido importantes funções na criação de programas e na expansão da pós-graduação, respectivamente nas regiões Sul e Sudeste; papel decisivo na criação e nos rumos da ANPEd; atuação destacada em diversos fóruns nos quais se discutiu e se tomou decisões e a partir dos quais se implementaram medidas a respeito de políticas de pósgraduação e frentes de atuação da ANPEd.

Por fim, apresentamos três resenhas de obras que tratam da pósgraduação em educação, que considera- 
mos as mais significativas sobre essa

modalidade de educação, relativamente pouco trabalhada. O livro A pós-

graduação na América Latina: o caso brasileiro, organizado por Rogério Cordova, Divonzir Gusso e Sérgio Luna, publicado em 1986, resgata questões relacionadas à gênese da pósgraduação no Brasil: financiamento, avaliação, atores e outros aspectos da área. O relatório Avaliação e perspectivas na área de educação: 1982-1991, resultante de ampla pesquisa coordenada pela ANPEd com financiamento do CNPq, pode ser considerado o trabalho coletivo mais valioso realizado pelos pesquisadores da área. Apesar de sua enorme importância, jamais foi divulgado amplamente; em boa hora a diretoria da ANPEd decidiu disponibilizá-lo no portal da entidade. A coletânea A bússola do escrever: desafios e estratégias na orientação de teses e dissertações, organizada por Lucídio Bianchetti e Ana Maria Neto Machado, publicada em 2002 pela Cortez e pela Editora da Universidade Federal de Santa Catarina (UFSC), e já em segunda edição, reúne longa série de artigos abordando os diferentes aspectos envolvidos no processo de orientação e de escrita de dissertações e teses, em especial após as mudanças implementadas pela CAPES no que diz respeito à redução dos prazos para a realização do mestrado e do doutorado e da exigência de que os pós-graduandos também apresentem publicações.

Com este conjunto de escritos, esperamos contribuir com novas fontes e abordagens diversas que podem servir de base para conhecer a nossa história, refletir sobre ela e fazer encaminhamentos que contemplem os passos já dados, mas que, ao mesmo tempo, apontem para formas e meios de superação de problemas que ainda persistem na pós-graduação em educação e que estão a demandar urgentes tomadas de posição.

Lucídio Bianchetti Osmar Fávero pela Comissão Editorial 